\section{Arab science to turn spring into summer}

For Arab scientists, the social revolution of the past year could be the light at the end of a long tunnel of hopelessness. To transform this optimistic mood into action, we must consider what we need to do to integrate science and technology into post-revolution development models, and what we can realistically accomplish.

The issue of governance is high on the agenda: it should be rooted in democracy and merit from now on. Innovative national systems are needed that reject trade-offs between educational reform and investment in education, research and design.

It is important that new science and technology development models are adapted to the socioeconomic environment and resist the temptation to enter into blind competition with developed countries.

Because scientific expertise will be needed to inspire these plans, it is imperative that models include strategies to reverse the scientific diaspora and to prevent the brain drain from Arab countries.

M. Dahmani Fathallah Arabian Gulf University, Bahrain; and Arab Policy Institute, Tunisia. d.fathallah@agu.edu.bh

\section{Climate results for public vetting}

Your discussion of the media's interest in the Berkeley Earth Surface Temperature (BEST) study - which released its results before peer review - implicitly acknowledges a change in the public authorization of scientific knowledge (Nature 478, 428; 2011). Yet few scientists would accept your branding of them as "purist" or "renegade" for their stance on the study's approach.

BEST members seek to promote a progressive image of science in a demanding, open and transparent society. Stimulated by an erosion of public trust in science, the publication of research before peer review aims to satisfy calls for greater public engagement with science.

Peer review after publication won't just confirm, adjust or correct the BEST results: it will demarcate soberly vetted scientific knowledge from the sometimes glib inferences an emotionally charged public makes through 'unruly' media that do not always report as scientists might want them to.

The progressive publication strategy of the BEST study exemplifies the emergence of a double-truth approach to the authorization of scientific knowledge on climate change. Mathis Hampel, Martin Mahony, Mike Hulme University of East Anglia, Norwich, UK. mathis.hampel@gmail.com

\section{Control the bonanza for research eggs}

The demand for women's eggs for research could soar alarmingly following news of a cloning technique that uses human oocytes to reprogram somatic cells to a state of pluripotency (S. Noggle et al. Nature 478, 70-75; 2011).

The mean number of eggs given by each woman during the study was 16.9 , with one donating 26 eggs. This is more than many fertility doctors would consider optimal and increases the risk of ovarian hyperstimulation syndrome. The researchers do not say that they halted hormone treatment in cases of overresponse, although they did stop it in under-responsive women.

Noggle et al. rightly anticipated concerns that payment for eggs could encourage financially disadvantaged women to take risks they might otherwise avoid. But US $\$ 8,000$, the amount paid by Noggle and colleagues, would be a temptation even to the well-off in these difficult economic times.

Some argue that women should evaluate for themselves the risks and benefits of providing eggs for research. But informed consent depends on provision of accurate information. Even after years of egg harvesting for fertility treatment, the risks to women - especially from some of the drugs and hormones used remain undercharacterized and poorly assessed, with inadequate follow-up and data collection.

Marcy Darnovsky Center for Genetics and Society, Berkeley, California,USA.mdarnovsky@ geneticsandsociety.org

Susan Berke Fogel Pro-Choice Alliance for Responsible Research, Van Nuys, California, USA.

Judy Norsigian Our Bodies Ourselves, Cambridge,

Massachusetts, USA.

\section{Food security: a role for Europe}

The European Union (EU) could contribute considerably to sustainable global food security because of its wealth of productive farmland (J. A. Foley et al. Nature 478, 337-342; 2011). Both production growth and increased sustainability therefore need to be at the heart of the Common Agricultural Policy.

As one of the largest global importers and exporters of food, the EU has significant leverage in, and responsibility for, the global food and nutrition agenda. Although the biggest impact on global food security will result from increased production in developing countries, the EU must play its part. It needs to protect and maintain its agricultural lands and increase food production.

This will mean producing more food with fewer resources, while minimizing environmental impacts at multiple spatial and temporal scales (called 'sustainable intensification'). Biotechnology will have a role in global food security, but it is unlikely to be the main solution. New approaches to managing farming systems and agricultural landscapes in an environmentally sensitive way could instead be more productive.
We therefore welcome the European Commission's proposals to increase the budget for agricultural research and innovation that is targeted at productive and ecological systems.

Tim Benton University of Leeds, UK.t.g.benton@leeds.ac.uk Tibor Hartel Ovidius University of Constanta, Romania. Josef Settele Helmholtz Centre for Environmental Research UFZ, Halle, Germany. On behalf of the other 6 authors of the Warsaw Consensus Statement (see go.nature.com/jzuytm).

\section{Food security: close crop yield gap}

Crop yields are rising more slowly than they were several decades ago (J. A. Foley et al. Nature 478, 337-342; 2011). This is especially evident in Europe, and has serious implications for its responsibilities in global food production.

In Denmark, France, Finland and Switzerland (see, for example, R. Finger Food Policy $35,175-182 ; 2010)$, the 'yield gap' has increased: the rate of growth in crop yields has declined, even though yield potential has risen over the past few decades owing to technological advances such as crop breeding.

Markets are one contributory factor: lower prices caused by reduced market support have decreased the incentive for investment in equipment, fertilizer, and so on. Also, by restricting the use of pesticides, for example, agricultural policies aimed at reducing environmental damage have hindered growth in crop yields.

Closing these yield gaps will ensure sufficient global food production and help towards food security. More incentives are needed, particularly as low-income countries are also confronted by sizeable yield gaps, for different reasons.

Robert Finger ETH Zurich, Switzerland.rofinger@ethz.ch 